AFRL-SR-BL-TR-01-

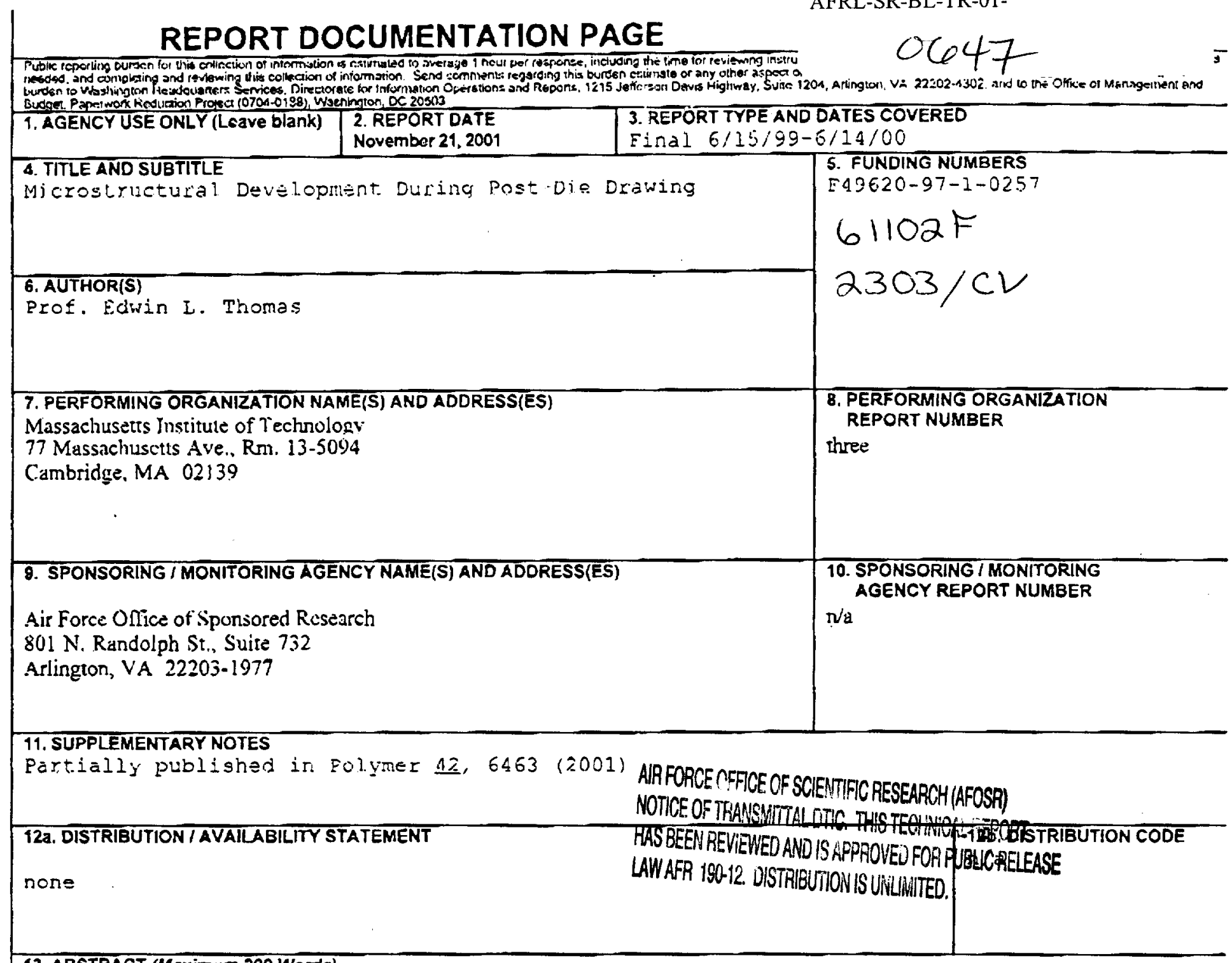

13. ABSTRACT (Maximum 200 Words)

see separate report

\title{
20020107006
}

\begin{tabular}{|c|c|c|c|}
\hline \multicolumn{3}{|c|}{$\begin{array}{l}\text { 14. SURJECT TERMS } \\
\text { Polymer blends, miscibility. ICST, laysered-silicale composites }\end{array}$} & \multirow{2}{*}{$\begin{array}{l}\text { 15. NUMBER OF PAGES } \\
3 \\
\text { 16. PRICE CODE } \\
\frac{1}{20 .} \\
\text { LIMITATION OF ABSTRACT }\end{array}$} \\
\hline $\begin{array}{l}\text { 17. SECURITY CLASSIFICATION } \\
\text { OF REPORT } \\
\text { unclassifi }=d\end{array}$ & $\begin{array}{l}\text { 18. SECURITY CLASSIFICATION } \\
\text { OF THIS PAGE } \\
\text { unclassified }\end{array}$ & $\begin{array}{l}\text { 19. SECURITY CLASSIFICATION } \\
\text { OF ABSTRACT } \\
\text { UnClassified }\end{array}$ & \\
\hline
\end{tabular}




\section{Microstructural Development During Post-Die Drawing}

Edwin L. Thomas

F49620-97-1-0257

This project concerned processing and characterization of materials: polymer-polymer blends and polymer-clay blends. The effort directed at processing of polymer-polymer blends concerned developing new ways to utilize a very high performance polymer polyparaphenylene (PX) by blending it with more easily processable and less expensive anorphous thermoplastics. We discovered that $\mathrm{PX}$ when mixed with polycarbonate exhibited a lower critical solution temperature behavior and that for certain compositions, a miscible blend was easily processable between $205.235^{\circ} \mathrm{C}$. Mechanical properties of these blends showed good retention of the outstanding properties of PX but were significantly easier to process.

We also studied processing-microstructurc-property relations for blends of a layered silicate and a triblock copolymer. In this case after organically modifying the clay, 0 $10 \%$ of clay was dispersed in a poly(styrene-isoprene-styrene)(PS1PI1PS) triblock copolymer exhibiting a lamellar microdomain morphology. The clay was intercalculated by the PS/PI/PS but only a minor amount of exfoliation of the clay layers occurred. Both simple cast polygranular isotropic samples and roll cast anisotropic films were produced. We studied the mechanical properties of these nanocomposites as a function of clay loading and as a function of the loading direction relative to the sample texture. Modulus, yield stress, toughness, strain hardening rate and residual plastic sirain all increased due to the addition of the clay. Evolution of the microstructure during deformation was possible via in situ small angle $x$-ray scatiering studies at Brookhaven. Results show the important role of inclusion of nanoparticles within the block copolymer layers and suggest nanocomposites based on fully exfoliated layers may have outstanding mechanical (as well as permeability etc) behavior. 
Final Technical Report

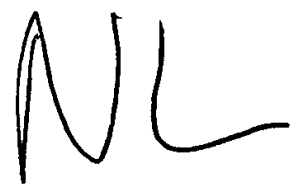

\section{Microstructural Development During Post-Die Drawing Edwin L. Thomas \\ F49620-97-1-0257}

\section{$\underline{\text { PX/PC Blends }}$}

Subsitituted poly(paraphenylene) derivatives (PX) have recently gained interest due to their unique properties. They are amorphous thermoplastics with relatively modest glass transition temperatures $\left(\mathrm{Tg} \sim 150^{\circ} \mathrm{C}\right)$, are soluble in various common organic solvents, and yet possess the strongest mechanical properties of any amorphous thermoplastic. However, the blend behavior of these polymers is relatively unexplored. We investigatged the phase behavior of PX and various thermoplastic blends and highlight the PX and polycarbonate (PC) blends.

We demonstrated that a on substituted poly(paraphenylene) derivative (PX) has a lower critical solution temperature (LCST) when blended with polycarbonate (PC). The miscibility was determined through enthalpy relaxation measurements due to the similar glass transition temperatures of the two components and a phase diagram was constructed using cloud point measurements. The LCST of PX1000/PC and PX1200/PC have been measured to be approximately $205 \mathrm{C}$ and $235 \mathrm{C}$ respectively. The storage moduli of the blends show that the miscible pairs in the single phase regime follow a linear behavior, while the two phase regime samples exhibit lower moduli which follow a simple Takayanagi series model. Blends of PX1200/PC may be used to lower the melt viscosity without significant reduction of the mechanical properties, thus helping overcome the difficult processing of pure PX (1).

\section{$\underline{\text { Layered-silicate/block copolymer nanocomposites }}$}

We have produced layered-silicate - lamellar triblock copolymer nanocomposites possessing a uniaxial texture. Solution blending of the layered-silicate solution with a block copolymer solution and subsequent roll-casting or solution casting and annealing resulted in an intercalated structure with only a low degree of exfoliation. Isotropic polygranular nanocomposite samples prepared by solution casting exhibit increase in modulus, higher yield stresses, earlier onset of strain hardening, increased strain hardening rate, and higher residual strains upon unloading with increasing layered-silicate content. In-situ and ex-situ deformation studies were performed along various directions on roll-cast nanocomposite samples to elucidate the effects of anisotropic particles upon deformation of the globally textured nanocomposite system. Deformation parallel to the roll-cast direction shows an earlier onset of strain hardening with modest increases in the modulus for particle-loaded films compared to that of the roll-cast neat triblock. The evolution of the triblock copolymer microstructure with applied strain shows the break up of the glassy polystyrene domains as was found for pure triblock 
copolymers. Upon unloading, the residual strains increase with increased loading content and the unloaded SAXS patterns show a distribution of lamellar spacings, suggesting significant back stresses due to the presence of the clay layers. Deformation perpendicular to the texture axis shows a dramatic increase in the tensile modulus compared to the unreinforced material. The microstructure evolution with strain in this direction is reminiscent of a neat triblock copolymer where at high strains $(\sim 100 \%)$, the layers buckle to form the chevron morphology and the lamellar normals continue to rotate away from the deformation direction with increasing strain at constant lamellar spacing. Unlike a pure triblock copolymer however, the chevron morphology remains locked in place upon unloading due to the presence of the layered-silicate particles.

Montmorillonite organically modified by dimehtyl benzyl hydrogenated-tallow ammounium with a cation exchange capacity of $125 \mathrm{meq} / 100 \mathrm{~g}$ were mixed in toluene with a lamellar forming 18-44-18K styrene-isoprene-styrene triblock copolymer (SIS). The samples were then either statically cast or roll-cast to induce orientation. The static cast samples showed no orientation and little intercalation of the polymer into the layered-silicates as evidenced by the $20 \AA$ spacing. The roll-cast samples showed that a fiber-like symmetry pattern exists in where the lamellae have lined up parallel to the flow direction however in a isotropic grain orientation when viewed perpendicular to the flow direction. TEM micrographs show that some exfoliation of the clay layers have occurred although most clay tactoids have retained the initial $20 \AA$ spacing as evidenced from WAXS. We believe this is the first report of an oriented block copolymer - layeredsilicate nanocomposite.

The isotropic samples show strain hardening at smaller strains with increasing clay content. The modulus increases approximately 2 -fold with about $10 \mathrm{wt} \%$ clay. For the oriented roll-cast samples, when deformed along the direction parallel to the layers, the modulus does not significantly change. Strain hardening begins at smaller strains with increasing clay content as observed in isotropic samples. For roll cast samples deformed in the perpendicular orientation, the modulus increases approximately 3 -fold with about $10 \mathrm{wt} \%$ clay content, with no significant changes in the strain hardening behavior.

In order to understand the evolution of the morphology during deformation oriented samples were also deformed in-situ on the $\mathrm{X} 27 \mathrm{C}$ beamline at the Brookhaven synchrotron. Results show that the samples deformed in the parallel direction behave similarly to that observed for neat lamellar triblock copolymers except that there exists a higher residual strain due to the presence of the clay. The samples deformed in the perpendicular direction show traces of the combination of the parallel, diagonal, and perpendicular behavior observed in pure block copolymers with the characteristic chevrons forming. However, when unloaded these chevron largely remain in place unlike the pure triblock copolymers. TEM shows that the clay tactoids have turned 900 from their original orientation by the deformation. During the strain hardening regime, the clay tactoids turn and kink along with the lamellar layers into the deformation direction, however during unloading, the clay prevents full recovery (2).

\section{References:}


(1). Ha, Y-H., Scott, C.E., and Thomas, E.L., "Miscible Blends of poly(benzoyl paraphenylene) and polycarbonate", Polymer $\underline{42}, 6463$ (2001).

(2). Ha, Y-H., and Thomas, E.L., "Deformation Behavior of a Roll-Cast LayeredSilicate/Lamellar Triblock Copolymer Nanocomposite", Macromolecules, submitted, November 2001. 